\title{
The Typology and Role of Online Information Sources in Destination Image Formation: An Eye- Tracking Study
}

Anastasia Mariussen. Oslo School of Management. Norway. Anastasia.Mariussen@mh.no

Cathrine Von Ibenfeldt. Oslo School of Management. Norway. Cathrine.Von.Ibenfeldt@mh.no

May Kristin Vespestad. Harstad University College. Norway. may.k.vespestad@hih.no

\begin{abstract}
The construct of destination image and its formation are well researched. Numerous studies are conducted to investigate how destination images impact tourists' attitudes, behaviour and destination choice and what factors influence their destination image formation. However, much of this research focuses on post-visit images, and little is still known about the actual process of destination image formation as it unfolds, particularly prior to visiting a destination. Understanding this process of image development is meanwhile critical, as tourist numbers worldwide continue to grow. Destinations face fiercer competition, and their expanding image representations on the Internet are more frequently created outside Destination Management Organisations' (DMO) offices. This study attempts to shed light on a destination image formation process prior to visiting a destination. By triangulating click-stream, eye-tracking, questionnaire and interview data, the work explores the types of online information sources involved in this process and examines their significance for destination image formation.
\end{abstract}

Keywords: Destination image formation, Information sources, Internet, Eye-tracking

\section{INTRODUCTION}

Although destination image literature has seen many valuable contributions from multiple disciplines, including sociology, anthropology, semiotics and marketing (Frias et al., 2008; Hankinson, 2004), some areas of this research still remain relatively unexplored (Beerli and Martin, 2004; Martin and Rodriguez del Bosque, 2007). For example, despite of the general consensus that image formation influences travellers' motivation, decision-making and behaviour (Choi et al., 
2007; Gallarza et al., 2002; Kim et al., 2014), little is still known about the actual process of destination image formation prior to visiting a destination (Baloglu and McCleary, 1999; Govers et al., 2007). Similarly, despite the acknowledged role the Internet plays in destination image formation (Frias et al., 2008), no further investigation into the individual impact of various online sources has been undertaken (Choi et al., 2007; Dwivedi, 2008). With the proliferation of the Internet and social media, which increasingly move the creation of destinationrelated information outside destination managers' offices (Choi et al., 2007; Frias et al., 2008; Govers et al., 2007), the importance and urgency of addressing these areas become ever so evident. A better understanding and appreciation of consumers' interaction with a variety of destination-owned and independent online information sources can provide valuable insights on how potential tourists travel the web (Govers et al., 2007), which sources they interact with when researching and planning their holidays and how these sources influence the way destinations are imagined, perceived and consumed (Hyun and O'Keefe, 2012).

This work seeks to shed more light on these questions. It explores the types of online information sources involved in destination image formation prior to visiting a destination, and examines their individual impact on this process. To address this aim, the research relies on a mixed-method design and triangulates click-stream, eye-tracking, questionnaire and interview data. In order to capture real-time destination image formation, we invite the participants to plan a trip to the sample destination that they have never visited before and record their online journey using eye-tracking technology. For the comparison of the perceived destination image prior and after the exposure to the Internet sources, questionnaire and interview methods are utilized.

The upcoming sections first review the extant literature on destination image formation and image formation agents, highlight current literature limitations and by so doing show where the original contribution is made. In the research methodology section that follows, the paper explains the methodological approach adopted. Thereafter, the findings are presented and discussed in light of the existing studies. In the conclusions, we highlight the contribution and put forward the appropriate recommendations for both theorists and practitioners.

\section{DESTINATION IMAGE FORMATION}


Destination images are of significance for both DMOs and their consumers. They enable DMOs promote destinations in the market place (Martin and Rodriguez del Bosque, 2007), uniquely position and differentiate them from competition (Hyun and O'Keefe, 2012), affect individual's subjective expectations and perceptions of a place (Gallarza et al., 2002) and influence tourists' attitudes, behaviours and destination choice (Choi et al., 2007; Echtner and Ritchie, 2003; Kim et al., 2014). At the same time, destination images help prospective tourists determine a destination's potential for satisfaction, lower risks associated with destination choice and serve as a mechanism for justification of destination selection (Beerli and Martin, 2004; Frias et al., 2008; Hankinson, 2004).

Given its significance, destination image is an extensively researched topic in tourism (Cakmak and Isaac, 2012; Pike, 2002). Numerous studies are dedicated to the relationship between destination image and its impact on consumer behaviour (Govers et al., 2007; Nicoletta and Servidio, 2012; Pratminingsih et al., 2014). Also, considerable progress is made in conceptualising and operationalization of the construct (Echtner and Ritchie, 2003; Gallarza et al., 2002; Mossberg and Kleppe, 2005; Yang et al., 2012), and the measurement scales for assessing destination image performance are developed and widely accepted (Beerli and Martin, 2004; Frias et al., 2008). In spite of some variations in conceptualisations (Baloglu and McCleary, 1999; Hyun and O'Keefy, 2012; Pike and Ryan, 2004), destination image is generally defined as a totality of a person's beliefs, ideas and knowledge about a destination's characteristics, as well as emotional thoughts and feelings towards the destination (Martin and Rodriguez del Bosque, 2007) .

How destination image forms in one's mind depends on several factors or socalled formation agents (Chon, 1991; Echtner and Ritchie, 2003; Gartner, 1993). Generally, researchers differentiate between two groups of such agents: personal or internal agents and stimulus factors. Among personal factors, psychological motivations, personal needs and preferences, and socio-demographic characteristics such as gender, age, education, family lifecycle, personality, lifestyle and social class are said to have an influence on how destination images are developed (Baloglu and McCleary, 1999; Martin and Rodriguez del Bosque, 2007). With regard to stimulus factors, previous experience and a variety and type of information sources are claimed to have an impact on the process of destination image formation (Beerli and Martin, 2004). 
According to the typology of destination image formation agents (Beerli and Martin, 2004; Choi et al., 2007; Gassiot and Coromina, 2013), previous experience and a visit to a destination are categorised as primary, personal, informal and independent information sources. These sources influence an individual's perception and image of a destination based on past experiences and internal information the individual holds of the destination. Another category of information sources is referred to as formal, secondary or external sources (Beerli and Martin, 2004; Phelps, 1986). These sources originate from the external stakeholders and are further divided into induced, autonomous and organic (Baloglu and McCleary, 1999; Gartner, 1993; Martin and Rodriguez del Bosque, 2007). Induced information sources are produced and sponsored by destinations, and for this reason are also called commercial (Choi et al., 2007; Hyun and O'Keefe, 2012). Examples of these are conventional promotion in mass media, celebrity endorsement advertising and other destination-initiated marketing activities. Autonomous information sources are unbiased and non-commercial. They reside in books, school education, TV programmes, documentaries and films (Choi et al., 2007). Finally, organic or social sources arise from friends and family (Hankinson, 2004).

Together, personal and stimulus formation agents contribute to the development of the overall or compound destination image, which further consists of a cognitive and an affective component (Lin et al., 2007; Pan and Ryan, 2007; Pike and Ryan, 2004). The cognitive component is comprised of the beliefs and knowledge a person holds about the specific attributes and physical properties of a destination (Martin and Rodriguez del Bosque, 2007). The affective component, in turn, refers to the individual's feelings in relation to a destination (Frias et al., 2008; Martin and Rodriguez del Bosque, 2007).

Although the significance of many of the outlined sources in creating a destination image and influencing destination choice is well documented ( $\mathrm{Li}$ et $a l ., 2009$ ), our understanding of the individual and specific source types, such as the various Internet channels and digital media, remains limited (Choi et al., 2007; Dwivedi, 2008; Govers et al., 2007; Kim et al., 2014). Broadly, it is known that the Internet as a whole has many potential benefits for destination image formation (Castaneda et al., 2007; Hays et al., 2013; Pan and Li, 2011). For example, Hyun and O'Keefe (2012) argue that Internet enables a 24-hour 
interaction with a destination prior to the actual travel and at a place and time convenient for consumers, and reduces the intangibility of a destination by inviting consumers to familiarise themselves with the destination through rich two- and tree-dimensional images and virtual tours. However, while the Internet's role in destination image formation is acknowledged (Li et al., 2009), there is still relatively little research about the individual influence of the different types of Internet sources or Internet channels on the process of destination image formation. In this paper, we investigate destination image formation prior to visiting a destination and focus on the types and significance of different online information sources in this process. More specifically, we set the following objectives:

1) To explore the types of online information sources involved in destination image formation prior to visiting a destination.

2) To examine the importance of these online information sources in the process of destination image formation.

\section{RESEARCH METHODOLOGY}

\subsection{Research Approach}

For the achievement of the study objectives, a mixed-method research design is adopted to capture the types of information sources used before and during the search, as well as their impact on the prior and post-search image. In previous works studying destination image quantitative methods have been prevalent (Dwivedi, 2008; Gallarza et al., 2002; Pike, 2002). These methods, however, have been criticised for encouraging respondents to think in prescribed and predetermined ways (Govers et al., 2007) instead of capturing the image that people have of a destination in their own words. Quantitative methods have also been accused of being over-reliant on scales measuring destinations' attributes or respondents' cognitive image of a destination, leaving little room for expressing what respondents feel towards a place (affective image) (Govers et al., 2007). As a result, scholars have called for more research using unstructured or qualitative instruments in order to allow respondents to freely express what they know of and feel towards a destination (Cakmak and Isaac, 2012; Choi et al., 2007; Govers et $a l$., 2007). Generally, qualitative methods are useful because they aid in a more in-depth understanding of the phenomenon, allow to approach areas with limited 
previous research and support theory development (Gill and Johnson, 1997; Gummesson, 1991). Since this paper seeks to both expand existing knowledge and taps into the under-researched area, the mix of qualitative and quantitative techniques is considered appropriate. The reasons for adopting a mixed-method approach are several. The combination of semi-structured questionnaires, eyetracking, click-stream and interviews provides a richer understanding of the phenomenon, enables triangulation, compensates for the weaknesses of different data collection techniques, and increases research reliability and validity (Creswell and Clark., 2011; Denzin and Lincoln, 2011).

\subsection{Data collection}

To capture the types of sources that people interact with on the Internet, we sought to emulate real life travel-planning situations. We invited the respondents to plan a trip to Morocco and recorded the process by means of eye-tracking technology. The overall data collection process was divided into three stages: presearch questionnaire, a trip planning exercise, and post-search questionnaire and interview. The trip planning methodology has been successfully employed in a number of studies on online search behaviour. Pan and Fesenmaier (2006), for example, utilised online vacation planning exercise together with click-stream analysis to investigate the micro-level process of vacation planning on the Internet. Similarly, Jordan et al. (2013) used this technique supported by eyetracking data to study online travel information search from a cross-cultural perspective.

\section{Screening Questionnaire}

Prior to the actual data collection, the participants were asked to complete a brief screening questionnaire to ensure they had sufficient computer and Internet experience (Jordan et al., 2013; Pan and Fesenmaier, 2006), did not have any visual impairments that could disturb eye-tracking (Balatsoukas and Ruthven, 2012) and had not previously visited the sample destination of Morocco (Pan and Fesenmaier, 2006). The screening questionnaire was distributed to the potential sample via email, and an additional invitation with the link to the questionnaire was posted on the university's learning platform (Cutrell and Guan, 2007). In total, 9 university students met our selection criteria and were invited to participate. Given the inductive-deductive nature of the study's inquiry and its 
reliance on open eye-tracking, a small sample size was both acceptable and advisable. This is because eye-tracking implied extensive data processing, and qualitative analysis of varied datasets involved demanding treatment of highly unstructured data (Cutrell and Guan, 2007).

Among qualified participants, 5 were females and 4 were males. Their average age was 24.5 and self-reported vision ranged between normal (6) and corrected normal (3). All participants were frequent computer and Internet users. On the average, they used computer for more than 42 hours a week and 34 hours of this time constituted the usage of the Internet (Balatsoukas and Ruthven, 2012).

To ensure that the screening questionnaire did not prompt the participants to research Morocco before the actual trip planning exercise took place, they were offered five destinations (Morocco, Dubai, Florida, Wales, Canary Islands) and asked whether they had visited them. Morocco was selected for the exercise due to the likeliness that the participants wouldn't have previous experience with the destination (Pan and Fesenmaier, 2006), as Morocco does not constitute a popular destination among Norwegians.

\section{Stage 1: Pre-Search Questionnaire}

Following screening, the qualified participants were invited to the laboratory, where they started by filling in the pre-exercise semi-structured questionnaire. The aim of the questionnaire was threefold. First, we wanted to obtain additional background information, including the participants' travel experience and prior skills in using the Internet for vacation planning (Gursoy and McCleary, 2004; Jordan et al., 2013). From these questions we learnt that the average number of trips the respondents had per year was 5, and their self-assessed tourism knowledge was described as fair (6), good (2) or very good (1). 8 of them always used the Internet to plan their trips, while one uses the Internet for this purpose $a$ fair amount.

Further, we sought to identify what the respondents' baseline image of Morocco was before the search. For this purpose, we relied on the accepted measures of overall image (positive-negative; good-bad) (Baloglu and McCleary, 1999) and an open-ended free-elucidation question designed by Govers et al. (2007). The open question suggested that the respondents should image they would visit Morocco for the first time and were encouraged to tell a story about 
what they thought their experiences would be like. They were asked to describe the images and thoughts that came to their mind and explain what they would see, feel, hear, smell and taste there (Govers et al., 2007). The cognitive and affective measures, typically used in destination image measurement studies, were not included not to influence respondents' perceived destination image (Lorigo et al., 2008).

Finally, we were interested to know which sources influenced the formation of the baseline image of Morocco. The list of sources was based on the measures from previous studies and included tourist brochures, advertising, travel agency staff, Internet, friends and family, guidebooks, news, articles, reports, documentaries and TV-programmes (Baloglu and McCleary, 1999).

\section{Stage 2: Trip Planning Exercise}

Upon the completion of the pre-search exercise and the calibration of the eyetracking equipment (Hurley et al., 2013), the respondents started a trip planning exercise. They were instructed to plan and "purchase" a flight and hotel in Casablanca for two people within a specified period of time. We requested them to perform the task in the way they would normally do and based on the budget that they normally disposed for holidays. Destination and time period were predefined for better comparison of participants' online journeys, while there were no restrictions with the regard to the time for the exercise.

During the online search activity, we recorded the participants' eye movements using an eye-tracking device (Tobii X2-60). The eye tracking system captured data at $60 \mathrm{~Hz}$. The minimum duration of a fixation was set to 100 (milliseconds). This time limit was convenient for differentiating a fixation from a saccade (a rapid eye movement between fixations), which normally lasted less than 100 milliseconds (Duchowski, 2002).

Eye-tracking was a preferred data collection method because of its documented benefits. Despite their distinct advantages, the traditional methods used to understand web behaviour such as diaries, think-aloud techniques and post-search interviews all give room for undesired post-rationalisation (Elling et al., 2012). Less intrusive eye-tracking, on the contrary, records users' real time eyemovements (such as the number of fixations and fixation length) and precisely reflects moment-to-moment cognitive processes (Balatsoukas and Ruthven, 2012; 
Franco-Watkins and Johnson, 2011). It provides rich and accurate data about the attention processing of specific information, and helps to understand how users interact with and evaluate the information, and make decisions (Cutrell and Guan, 2007).

For comparison reasons, we treated various types of sources as different areas of interest (AOIs) (Lorigo et al., 2008). Overall, we operated with six AOIs:

SEO: Organic or search engine optimised (SEO) results on general search engines such as Google and Bing

PPC: $\quad$ Paid or pay per click (PPC) search engine results

Referrals: Travel intermediaries that promote or distribute services on behalf of primary service providers (e.g., Expedia, Momondo, Skyscanner)

UGC: Websites with user-generated content (UGC) such as blogs, social media sites

Direct: Direct or primary service providers (e.g., Novotel.com, Norwegian.no)

Info: Infomediaries or websites providing independent travel informal (e.g., Wikipedia, government websites offering travel information and advice about other destinations).

The measures employed in the analysis of the sources' significance consisted of the typical eye-tracking metrics, including number of fixations, fixation time (sec) and duration of fixations (sec). A fixation is the most common type of eye movement data used for the comprehension of the online behaviour and the cognitive load associated with it. It is defined as a stable gaze on a specific area. As a rule, fixations last 150-600 milliseconds, however, longer fixations of 2 or 3 seconds are also possible (Cutrell and Guan, 2007).

\section{Stage 3: Post-Search Questionnaire and Interview}

After finishing the online search, the participants first completed a short follow-up questionnaire about their post-attitudinal evaluations of Casablanca as a holiday destination. Thereafter, like some previous studies (Gidlof et al., 2012), we 
showed them a video of their web search, and conducted a stimulated recall interview, asking them to explain their actions on the Internet.

Overall, four sets of data are generated: pre- and post-search questionnaires, eye-tracking and stemming from it click-stream, and interview data. Questionnaire data is used for the comparison of the overall destination image prior and after the exposure to the Internet sources. Whilst, eye-tracking, clickstream and interview data explicated real-time destination image formation and the types of online information sources involved in this process.

\section{FINDINGS AND DISCUSSION}

It is important to note that, similar to other studies on destination formation, this work represent a 'snap-shot' of the process. Gunn (1972) conceptualised image formation through a seven-phase travel experience:

1. Collection of mental images about travel experiences

2. Adjustment of the initial images by additional information

3. Decision to take a trip

4. Travel to the destination

5. Participation at the destination

6. Return home

7. Adjustment of images based on the travel experience

In this work we zoom into the first two stages of the aforementioned process. For the ease of data analysis, we present and structure the findings and discussion around the research objectives of the study: 1) An exploration of the types of online information sources involved in destination image formation prior to visiting a destination, and 2) the examination of the importance of these online information sources on destination image formation.

\subsection{Online Information Sources Involved in Destination Image Formation}

\section{Pre-Search Information Sources}

Following the question about the overall impression of Morocco, in the pre-search questionnaire, the respondents were asked to specify which sources influenced the image they held of this destination. As seen in table 1, the most significant 
information sources were friends and family, closely followed by the Internet and a range of autonomous sources, such as news, TV-programmes, articles and documentaries.

\begin{tabular}{llllll}
\hline Information source & Information source type & Min & Max & Mean & SD \\
\hline Friends and family & Organic & 4 & 7 & 6.22 & 0.97 \\
Internet & $\begin{array}{l}\text { Induced, organic, } \\
\text { autonomous }\end{array}$ & 1 & 7 & 5.56 & 2.00 \\
& Autonomous & & & & \\
News & Autonomous & 1 & 6 & 4.22 & 1.48 \\
TV-programmes & Autonomous & 1 & 6 & 3.55 & 1.74 \\
Articles & Autonomous & 1 & 5 & 3.44 & 1.74 \\
Documentaries & Autonomous & 1 & 7 & 3.11 & 1.97 \\
Guidebooks & Autonomous & 1 & 5 & 2.67 & 1.80 \\
Reports & Induced & 1 & 5 & 2.55 & 1.51 \\
Advertising & Induced & 1 & 4 & 2.33 & 1.11 \\
Travel agency staff & Induced & 1 & 5 & 2.33 & 1.80 \\
Tourist brochures & T. & 1 & 5 & 2.11 & 1.45 \\
\hline
\end{tabular}

Table 1. Types of information sources

Adopting the typology of sources by Baloglu and McCleary (1999), it can, therefore, be argued that organic and autonomous sources appear to be the information sources influencing destination image formation the most. However, given that all Internet sources are treated collectively as one source, this explanation is only partial and largely misleading, because the Internet also hosts induced, organic and autonomous information. The reliance on this information typology, hence, only presents a part of the picture. To generate a more holistic understanding of the different source types, we perform a detailed analysis of all online sources used by the respondents during their trip planning exercise.

\section{Typology of Online Information Sources}

In total, we differentiate between 6 general types of online information sources and place them under the same categories of induced, organic and autonomous sources. To the induced online sources category, we can add paid search engine results (PPC), referrals or online intermediaries, and information provided 
directly by primary service providers. A part of organic sources are organic search engine results (SEO) and user-generated content (UGC), whilst among autonomous sources there are infomediaries, providing independent travel information.

A differentiation between these sources is not always easy to make. For example, Tripadvisor, that just a short time ago was referred to as a UGC site, has now moved to the referrals category. In addition to offering a platform for travellers' reviews, it now has adopted the features of the typical travel or vertical search engines such as Travelmarket, Skyscanner and Expedia. In turn, what used to be pure travel search engines have introduced the elements of user-generated content by either collecting their own customer reviews (e.g., Booking.com) or integrating the reviews from Tripadvisor. The explanation behind these changes is the intermediaries' attempt to create one-stop shops, capitalising on the most trusted sources of information - organic customer reviews.

A further analysis of the overall amount of 43 unique websites, based on the click-stream data, shows that the referrals group exhibits most variation in sources. Referrals can namely be broken down into 6 types:

1. Travel agent (e.g., Travellink, Reisefeber, Ticket, Destinia, Startour)

2. Marketplace (e.g., Airbnb, Finn.no)

3. Recommendation engines (e.g., Tripadvisor)

4. Price comparison sites (e.g., Skyscanner, Momondo, Kelkoo, Travelmarket)

5. Accommodation distributors (e.g., Booking.com, Hotels.com, Hostels.com)

6. Flight distributors (e.g., Billigeflyturer).

The other online sources types appear to be more homogenous. To exemplify, the respondents used only 2 types of search engines (Google and Bing) and 1 type of UGC, i.e. blogs (e.g., lapoint.no, determulig.no). The selection of infomediaries is also relatively limited (e.g., Wikipedia, Landsider.no).

\subsection{The Role of Information Sources in Destination Image Formation}

Online Sources with Most Visits and High Cognitive Load 
Of the total amount of 43 unique websites, the most visited were referrals. They comprised 28 unique sites or $65 \%$ of all websites. The distribution of unique websites among other sources types was as follows: infomediaries (5), service provider-owned websites (5), blogs (3), SEO and PPC (2). The click-stream data indicates that an average time spent on the trip planning exercise was 21:20 min. Of all online sources, the participants spent most of their time on referrals $(\mathrm{M}=13: 49)$ and SEO (M=2:38), while time spent on primary service providers' websites, infomediaries, PPC and UGC was less than 1 min.

These results are further supported by the analysis of eye-tracking data (Table 2), which shows that there is a significant difference between the average time of two source types: referrals and SEO. On average, participants used significantly more time on each fixation when using SEO ( $\mathrm{M}=264$ milliseconds, $\mathrm{SE}=12,04)$ compared to referrals $(\mathrm{M}=231$ milliseconds, $\mathrm{SE}=6,37), t(94,4)=-2,422, p<.05, r=$ .24. In addition, there is a significant difference between the average amount of fixations between these two channels. On average, participants fixated more times when visiting referrals $(M=111, S E=15,78)$ compared with $S E O s(M=42, S E=$ $5,54), t(159,5)=4,126, p<.01, r=.31$.

\begin{tabular}{lllllll}
\hline Ocular indices & Referrals & SEO & Direct & Info & PPC & Blogs \\
\hline Number of fixations per channel & 14615 & 2549 & 836 & 873 & 952 & 314 \\
Fixation time per channel (sec) & 3369 & 673 & 220 & 203 & 244 & 76 \\
Durations of fixations (sec) & 0,23 & 0,26 & 0,26 & 0,2 & 0,26 & 0,24 \\
\hline
\end{tabular}

Table 2. Average ocular indices for participants by online channels

The interview question about the purposes of using various websites reveals that referrals were used at all stages of the decision-making cycle. In other words, they were visited in order to gain qualitative and quantitative information about the destination, identify and evaluate travel alternatives, limit and sort travel options, choose the best offer and purchase it. The same cannot be applied to other information sources. For instance, SEO was primarily used for information search, while service provider-owned websites were visited to check prices, assess available travel options and determine selection criteria for purchase decision. 


\begin{tabular}{|c|c|c|c|c|}
\hline Referral & Visitors & Average time per fixation (sec) & Total amount of fixations & $\begin{array}{l}\text { Total } \\
\text { fixation } \\
\text { time } \\
\text { (sec) }\end{array}$ \\
\hline Solfaktor & 2 & 0,30 & 297 & 90,7 \\
\hline Kelkoo & 1 & 0,29 & 299 & 87,4 \\
\hline Billigeflyturer & 1 & 0,29 & 152 & 43,9 \\
\hline Travellink & 1 & 0,28 & 1107 & 307,0 \\
\hline Ving & 2 & 0,28 & 233 & 73,1 \\
\hline Supersaver & 2 & 0,27 & 1070 & 362,6 \\
\hline Hostels.com & 1 & 0,25 & 319 & 80,7 \\
\hline Bravofly & 1 & 0,25 & 136 & 34,3 \\
\hline Momondo.no & 1 & 0,25 & 33 & 8,3 \\
\hline Skyscanner & 2 & 0,25 & 994 & 250,7 \\
\hline Restplass & 2 & 0,25 & 154 & 38,6 \\
\hline Airbnb & 1 & 0,25 & 828 & 206,6 \\
\hline Kilroy & 1 & 0,24 & 140 & 34,1 \\
\hline Amoma.com & 1 & 0,23 & 132 & 31,0 \\
\hline Finn & 4 & 0,23 & 1322 & 325,1 \\
\hline Startour & 1 & 0,23 & 13 & 3,0 \\
\hline Rome2Rio & 1 & 0,23 & 129 & 29,3 \\
\hline Destinia.com & 1 & 0,23 & 36 & 8,1 \\
\hline Reisefeber & 2 & 0,22 & 572 & 148,8 \\
\hline Ticket & 3 & 0,22 & 574 & 125,0 \\
\hline Booking.com & 2 & 0,22 & 370 & 82,1 \\
\hline Expedia & 4 & 0,21 & 665 & 144,6 \\
\hline Travelmarket & 2 & 0,21 & 305 & 192,2 \\
\hline Hotels.com & 3 & 0,20 & 1002 & 203,4 \\
\hline Cntraveller.com & 1 & 0,19 & 5 & 1,0 \\
\hline Tripadvisor & 5 & 0,19 & 3131 & 516,6 \\
\hline Travel.com & 1 & 0,19 & 52 & 9,7 \\
\hline Reise.no & 1 & 0,18 & 369 & 66,6 \\
\hline Ferietipset.no & 1 & 0,16 & 17 & 2,7 \\
\hline Gotogate & 2 & 0,14 & 68 & 17,0 \\
\hline
\end{tabular}

Table 3. Cognitive load related to referrals 
A micro-level examination of the eye-tracking data illustrates that Tripadvisor (5), finn (4), Expedia (4), Hotels.com (3) and Ticket (3) received most unique visits, showing which sites the respondents visit most often (Table 3). The data also shows that Tripadvisor, Finn, Travellink, Supersaver, Hotels.com, Skyscanner and Airbnb encounted the highest total amount of fixations and total fixation time. This implies that the respondents investigated these sites thoroughly, looked at more website elements, focused longer and used a variety of referral types with travel agencies (Travellink, Supersaver) and marketplaces (Finn, Airbnb) being most preferred.

Sorting the data by average time per fixation additionally shows that only five of these (i.e. Travellink, Supersaver, Skyscanner, Airbnb and Hotel.com) induced a fair amount cognitive load every time the respondents focus on the website's elements. Among the referrals arousing highest cognitive thinking was a travel agency Solfaktor (visit by 2 unique visitors), a price comparison site Kelkoo (visited by 1 unique visitor) and a flight distributor Billigeflyturer (visited by 1 unique visitor). The interpretation of the latter finding needs to be approached with caution due to the low number of respondents. The reasons for increased cognitive load can, for example, be the reduced usability or increased complexity of the websites. Correspondingly, the reason for lower cognitive load of the most visited websites might be the familiarity of the respondents with those sites. As one of the respondents stated during the interview, most websites were visited out of "habit". Several respondents reiterated this point by saying they had a standard route that they always followed, and that they deviated from it only when the "usual websites" did not solve their needs

\section{Search Patterns}

A qualitative analysis of the click-stream identifies a few interesting search patterns. First, the DMO-owned website visitmorocco.com was not represented in any of the searches. This is despite the fact that most of the respondents searched in English. Second, Google was undoubtedly the most preferred and trusted search engine, "it gives you everything you need". It was used both as a starting point and a base with the overview of the results, which the participants continuously returned to throughout the search. One of the respondents accidentally started search on Bing, but as soon as he realised it was not Google, switched the search engine. Google also seemed to be more used in the beginning 
of the search to identify potentially interesting websites. Many respondents took a note of these websites by right clicking on them and opening them in different tabs. Often such note taking resulted in many opened tabs, many of which the respondents only briefly checked or in some cases they did not even return to them. It seems that taking note of the website suggested by Google gave the respondents a sense of control and reasoned action. One more interesting observation is which sites the respondents perceived they purchased through. It appears that when the purchase took place through some of the referrals (e.g., Travelmarket), which for the actual purchase sent customers to yet a new referral (e.g., Venere.com), the respondents still perceived that they are buying via the initial referral. On the question whether they were familiar with the sites they were referred to, they answered no, but quickly explained that they came from the trusted websites and, therefore, did not need to worry about the security or brand name of the site. Finally, it was interesting to see how the respondents were multitasking. Frequently, they started search on travel agents sites, and quickly moved to a different site to initiate a similar search. In a few instances, the impatience interfered the planned sequence for search, and the participants got distracted by yet new tasks and websites.

\section{Pre- and Post-search Image of Morocco}

On average, each respondent visited 8.67 websites. According to the questionnaire and interview data collected, these websites seem to have influenced participants overall image of Morocco (Table 4). Even though two respondents stated that their impression of Morocco prior and after the online search stayed unchanged, the triangulation of the questionnaire and interview data shows a slightly positive change in the overall image of the selected destination. On the Likert scale question about the overall image of Morocco (1 - highly negative; 7 - highly positive), the mean before the online information search was at 4.44 , whilst after the search this mean increased to 4.89. An additional question on the overall image of Morocco (1-very bad; 7-very good) similarly illustrated a minor change between prior-search image with the mean of 4.67 and post-search image with the mean of 4.89 . 


\section{Prior-search destination description}

Security, markets in Marrakech, different smells, large open jars with spices, good smells, Muslim country, covered women faces, dress code, a lot of exciting things, spicy food which I like, new culture, new food.

Differences, different culture, security, afraid of men, exciting culture, food, wine, Aladdin, carpets, loud voices in the streets, atmosphere.

People, climate, food, want to put on the local clothes, exciting to look at cutlery, plates, jewellery, furniture, would like to see it for myself.

Very warm, desert, spices, a lot of people in the streets, patterned clothes, markets, long shirts, temples.

Warm climate, lack of things to see and activities, only hotel activities, pick pockets, no expectations to food, would travel there.

African northern coast, good surfing opportunities, men with curled dark hair and beard, positive atmosphere, positive people.

Exotic, exciting food, big markets full of spices and carpets, colourful places, Arabic architecture, a lot of people in the streets, beautiful old city.

Food, beverages, local traditions, culture, big markets.

Warm, surfing, local people, openness, hospitality.

\section{Post-search destination description}

I would like to travel there first and experience it myself.

Same impression, but more curious, a bit of everything, shopping, architecture, clear difference between the rich and the poor.

Will not visit Morocco, prefer countryside.

No change in image.

As expected, positively surprised over lower prices.

More exotic and exciting than previously anticipated.

Still a surfing place for me, will not go to Morocco to lay on the beach.

Table 4. Free elucidation of pre- and post search perceived destination image

The answers to the open-ended questions and quotes from the interviews further illustrate some changes in the descriptions of the destination (Table 4). For example, in the pre-search questionnaire, one respondent depicted the destination in terms of the cognitive attributes of the place such as "food and beverage, local traditions, culture, large markets". After trip planning, this respondent portrayed the destination in both cognitive and affective terms and refers to it as "more exotic and exciting than I thought". Another respondent demonstrated the 
contribution of online sources to the cognitive image of the destination. Before the search, the participant expressed her feelings towards Morocco and summarises extant mental images of the destination in the following way:

"I have never been to Morocco. The first I think about is being careful. Would there be any reason for me as a woman to worry since it is another culture? I feel intimidated by the men despite the fact that I have not been there. On the other side, I see an exciting culture with food and wine. When I think of Morocco I think of Aladdin, carpets. I picture loud voices in the streets. The atmosphere ..."

After the search, the same person appeared to be more knowledgeable about the destination's attributes (e.g., shopping, architecture) and described Morocco as follows:

"My impression stays the same, but I am a bit more curious about how it actually is, both in the tourist areas and outside. It seems like Morocco has a bit of everything, shopping, and architecture. There is a clear distinction between the poor and the rich".

\section{CONCLUSIONS}

This study makes an original contribution to knowledge by filling in two major gaps in destination image formation literature. It sheds more light on the process of destination image formation prior to a destination visit (Govers et al., 2007), and captures a part of this process (i.e. modification of the initial images by additional online information) in real-time as it unfolds (Gunn, 1972). Previous studies largely investigated this question by asking respondents to think back and report on the used information sources upon arrival to or when leaving the destination (Frias et al., 2008). Additionally, many extant studies treated the Internet in its totality and as one information source type (Choi et al., 2007; Kim et al., 2014), something that only highlighted the significant role of the Internet but did not explain what exactly on the Internet played a role (Dwivedi, 2008). In this work, we propose a typology of online information sources and elucidate their individual significance for image formation. In particular, we find that search engines (in this case Google) and referrals with travel agents and marketplaces comprise the most influential online sources of information. By breaking the Internet down into several source types, we further identify that the most 
significant destination image formation agents are organic sources such as friends and family, followed by induced online sources or more precisely referrals, and organic search engine results.

Methodologically, the paper adds value by proposing eye-tracking as a new way of measuring destination image formation, and shows how eye-tracking can help to understand the real-time formation process in a more precise way (Elling et al., 2012; Jordan et al., 2013).

\section{LIMITATIONS AND FURTHER RESEARCH RECOMMENDATIONS}

The work has a few notable limitations. The first limitation is the limited number of participants. Although such sample size is acceptable in open eye-tracking studies and is consistent with the study research question, it does not provide generalizable findings. To compensate for this limitation, method and data triangulation were exploited and generated rich data necessary for analysis. The second weakness is that we only considered a part of the overall decision-making process. Finally, we did not take into consideration different types of search behaviour, which are known to influence what websites people visit. Lorigo et al. (2008) suggest that search behaviour can be divided into navigational, informational and transactional. Similarly, Kim et al. (2014) argue that online behaviour can be categorised as searching or surfing. Although we attempted to neutralise this effect by instructing the respondents "to plan and purchase" a trip (i.e. inviting to surf and search), the search style can be argued be closer to transactional. This is because the destination was already selected upfront. What remained was booking of accommodation and flights. These shortcomings and other related issues should be addresses by further research. Future works are encouraged to explore and develop innovative methodologies to gain a better understanding of destination image formation as it unfolds and to conduct quantitative research to further statistically test the propositions of this study.

\section{REFERENCES}

BALATSOUKAS, P.; RUTHVEN, I. (2012): “An Eye-Tracking Approach to the Analysis of Relevance Judgments on the Web: The Case of Google Search Engine", Journal of the American Science and Technology, vol. 63, n.9: 17281746. http://dx.doi.org/10.1002/asi.22707 
BALOGLU, S.; MCCLEARY, K.W. (1999): “A Model of Destination Image Formation”, Annals of Tourism Research, vol. 26, n.4: 868-897. http://dx.doi.org /10.1016/S0160-7383(99)00030-4

BEERLI, A.; MARTIN, J.D. (2004): "Factors Influencing Destination Image", Annals of Tourism Research, vol. 31, n. 3: 657-681. http://dx.doi.org/10.1016/jnna $\underline{1 \mathrm{~s} .2004 .01 .010}$

CAKMAK, E.; ISAAC, R.K. (2012): "What Destination Marketers Can Learn From Their Visitors' Blogs: An Image Analysis of Bethlehem, Palestine", Journal of Destination Marketing \& Management, vol. 1, n. 1-2: 124-133. http://dx.doi.org/10.1016/j.jdmm.2012.09.004

CASTANEDA, J.A.; FRIAS, D.M.; RODRIGUEZ, M.A. (2007): “The Influence of the Internet on Destination Satisfaction", Internet Research, vol. 17, n. 4: 402420. http://dx.doi.org/10.1108/10662240710828067

CHOI, S.; LEHTO, X.Y.; MORRISON, A.M. (2007): "Destination Image Representation on the Web: Content Analysis of Macau Travel Related Websites", Tourism Management, vol. 28, n. 1: 118-129. http://dx.doi.org/10.16/j. $\underline{\operatorname{trman} .2006 .03 .002}$

CHON, K.S. (1991): “Tourism Destination Image Modification Process. Marketing Implications", Tourism Management, vol. 12, n. 1: 68-72. http://dx.doi.org/10.1016/0261-5177(91)90030-W

CLARK, V.L.P.; CRESWELL, J.W. (2011): Designing and Conducting Mixed Methods Research. California: Thousand Oaks.

CUTRELL, E.; GUAN, Z. (2007): "What are You Looking at? An Eye-Tracking Study of Information Usage in Web Search", proceeding of the Computer / Human Interaction Conference, San Jose, California, USA, 28 April - 3 May. http://dx.doi.org/10.1145/1240624.1240690

DENZIN, N.K.; LINCOLN, Y.S. (Eds.) (2011): The SAGE Handbook of Qualitative Research. California: Throusand Oaks. Sage.

DUCHOWSKI, A.T. (2002): “A Breadth-First Survey of Eye Tracking Applications", Behaviour Research Methods, Instruments, and Computers, vol. 34, n. 4: 455-470. http://dx.doi.org/10.3758/BF03195475 
DWIVEDI, M. (2008): “Online Destination Image of India: A Consumer Based Perspective", International Journal of Contemporary Hospitality Management, vol. 21, n. 2: 226-232. http://dx.doi.org/10.1108/09596110910935714

ECHTNER, C.M.; RITCHIE, J.R. (2003): "The Meaning and Measurement of Destination Image”, Journal of Tourism Studies, vol. 14, n. 1: 37-48.

ELLING, S.; LENTZ, L.; DE JONG, M. (2012): “Combining Concurrent ThinkAloud Protocols and Eye-tracking Observations: An Analysis of Verbalisations and Silences", Transactions on Professional Communication, vol. 55, n. 3: 206220. http://dx.doi.org/10.1109/TPC.2012.2206190

FRANCO-WATKINS, A.M.; JOHNSON, J.G. (2011): "Decision Moving Window: Using Interactive Eye Tracking to Examine Decision Processes", Behaviour Research, vol. 43: 853-863. http://dx.doi.org/10.3758/s13428-011$\underline{0083-y}$

FRIAS, D.M.; RODRIGUEZ, M.A.; CASTANEDA, J.A. (2008): “Internet vs. Travel Agencies on Pre-visit Destination Image Formation: An Information Processing View", Tourism Management, vol. 29, n. 1: 163-179. http://dx.doi.org/10.1016/j.tourman.2007.02.020

GALLARZA, M.G.; SAURA, I.G.; GARCIA, H.C. (2002): “Destination Image: Towards a Conceptual Framework", Annals of Tourism Research, vol. 29, n.1: 5678. http://dx.doi.org/10.1016/S0160-7383(01)00031-7

GARTNER, W.C. (1993): "Image Formation Process", Journal of Travel and Tourism Marketing, vol. $2, \quad$ n. $\quad 2 / 3$ : $191-215$. http://dx.doi.org/10.1300/J073v02n02_12

GASSIOT, A.; COROMINA, L. (2013): "Destination Image of Girona: An Online Text-Mining Approach”, International Journal of Management Cases, vol. 15, n.4: 301-314.

GIDLOF, K.; HOLMBERG, N.; SANDBERG, H. (2012): "The Use of Eyetracking and Retrospective Interviews to Study Teenagers' Exposure to Online Advertising", Visual Communication, vol. 11, n. 3: 329-345. http://dx.doi.org/10.1 $\underline{177 / 1470357212446412}$ 
GILL, J.; JOHNSON, P. (1997): Research Methods for Managers (2 ed.). London: Paul Chapman Publishing Ltd.

GOVERS, R.; GO, F.M.; KUMAR, K. (2007): "Virtual Destination Image. A New Measurement Approach", Annals of Tourism Research, vol. 34, n. 4: 977997. http://dx.doi.org/10.1016/j.annals.2007.06.001

GUMMESSON, E. (1991): Qualitative Methods in Management Research. London: Sage Publications.

GUNN, C. (1972): Vacationscape. Bureau of Business Research, University of Texas, Austin, TX..

GURSOY, D.; MCCLEARY, K.W. (2004): “An Integrative Model of Tourists' Information Search Behaviour”, Annals of Tourism Research, vol. 31, n. 2: 353373. http://dx.doi.org/10.1016/j.annals.2003.12.004

HANKINSON, G. (2004): "The Brand Images of Tourism Destinations: A Study of the Saliency of Organic Images", Journal of Product \& Brand Management, vol. 13, n. 1: 6-14. http://dx.doi.org/10.1108/10610420410523803

HAYS, S.; PAGE, S.J.; BUHALIS, D. (2013): "Social Media as a Destination Marketing Tool: Its Use by National Tourism Organisations", Current Issues in Tourism, vol. 16, n. 3: 211-239. http://dx.doi.org/10.1080/13683500.2012.662215

HURLEY, R.A.; OUZTS, A.; FISCHER, J.; GOMES, T. (2013): "Effects of Private and Public Label Packaging on Consumer Purchase Patterns", Packaging Technology and Science, vol. 26: 399-412. http://dx.doi.org/10.1002/pts.2012

HYUN, M.Y.; O'KEEFE, R.M. (2012): "Virtual Destination Image", Journal of Business Research, vol. 65, n. 1: 29-35. http://dx.doi.org/10.1016/j.jbusres.211.07. 011

JORDAN, E.J.; NORMAN, W.C.; VOGT, C.A. (2013): “A Cross-Cultural Comparison of Online Travel Information Search Behaviours", Tourism Management Perspectives, vol. 6: 15-22. http://dx.doi.org/10.1016/j.tmp.2012.11. $\underline{002}$

KIM, S.B.; KIM, D.Y.; WISE, K. (2014): “The Effect of Searching and Surfing on Recognition of Destination Images", Computers in Human Behaviour, vol. 30, n. 1: 813-823. http://dx.doi.org/10.1016/j.chb.2013.07.010 
LI, X.; PAN, B.; ZHANG, L.; SMITH, W.W. (2009): “The Effect of Online Information Search on Image Development: Insights from a Mixed-Methods Study", Journal of Travel Research, vol. 48, n. 1: 45-57. http://dx.doi.org/10.1177 $\underline{10047287508328659}$

LIN, C.H.; MORAIS, D.B.; KERSTETTER, D.L.; HOU, J.S. (2007): “Examining the Role of Cognitive and Affective Image in Predicting Choice Across Natural, Developed and Theme-Park Destinations", Journal of Travel Research, vol. 46: 183-194. http://dx.doi.org/10.1177/0047287506304049

LORIGO, L.; HARIDASAN, M.; BRYNJARSDOTTIR, H.; XIA, L.; JOACHIMS, T.; GAY, G.; GRANKA, L.; PELLACINI, F.; PAN, B. (2008): "Eye Tracking and Online Search: Lessons Learned and Challenges Ahead", Journal of the American Science and Technology, vol. 59, n. 7: 1041-1052. http://dx.doi.org/10.1002/asi.20794

MARTIN, H.A.; RODRIGUEZ DEL BOSQUE, I.A. (2007): "Exploring the Cognitive-Affective Nature of Destination Image and the Role of Psychological Factors in Its Formation", Tourism Management, vol. 29, n. 2: 263-277. http://dx.doi.org/10.1016/j.tourman.2007.03.012

MOSSBERG, L.; KLEPPE, I.A. (2005): "Country and Destination Image Different or Similar Image Concepts?”, The Service Industries Journal, vol. 25, n. 4: 493-503. http://dx.doi.org/10.1080/02642060500092147

NICOLETTA, R.; SERVIDIO, R. (2012): “Tourists' Opinions and Their Selection of Tourism Destination Images: An Affective and Motivational Evaluation", Tourism Management Perspectives, vol. 4: 19-27. http://dx.doi.org/10.1016/j.tmp .2012 .04 .004

PAN, B; FESENMAIER, D.R. (2006): “Online Information Search. Vacation Planning Process", Annals of Tourism Research, vol. 33, n. 3: 809-832. http://dx. doi.org/10.1016/j.annals.2006.03.006

PAN, L.; LI, X.R. (2011): "The Long Tail of Destination Image and Online Marketing", Annals of Tourism Research, vol. 38, n. 1: 132-152. http://dx.doi.org /10.1016/j.annals.2010.06.004

PAN, S.; RYAN, C. (2007): “Analyzing Printed Media Travelogues: Means and Purposes with Reference to Framing Destination Image", Tourism, Culture and Communication, vol. 7, n. 2: 85-97. doi.org/10.3727/109830407780339017 
PHELPS, A. (1986). Holiday Destination Image: The Problem of Assessment An Example Developed in Minorca. Tourism Management, vol. 7, n.3: 168-180. http://dx.doi.org/10.1016/0261-5177(86)90003-8

PIKE, S. (2002): "Destination Image Analysis - A Review of 142 papers from 1973 to 2000", Tourism Management, vol. 23: 541-549. http://dx.doi.org/10.1016/ $\underline{\mathrm{S} 0261-5177(02) 00005-5}$

PIKE, S: RYAN, C. (2004): "Destination Positioning Analysis through a Comparison of Cognitive, Affective, and Conative Perceptions", Journal of Travel Research, vol. 42: 333-342. http://dx.doi.org/10.1177/0047287504263029

PRATMININGSIH, S.A.; RUDATIN, C.L.; RIMENTA, T. (2014): "Roles of Motivation and Destination Image in Predicting Tourist Revisit Intention: A Case of Bandung - Indonesia", International Journal of Innovation, Management and Technology, vol. 5, n. 1: 19-24. http://dx.doi.org/10.7763/IJIMT.2014.V5.479

YANG, J.; HE, J.; YINGKANG, G. (2012): "The Implicit Measurement of Destination Image: The Application of Implicit Association Tests", Tourism Management, vol. 33: 50-52. http://dx.doi.org/10.1016/j.tourman.2011.01.022 